\title{
Information Visualization Analysis of Academic Development of CSSCI Papers on Intercultural Communication from 2006-2015
}

\author{
Chuanming Yang ${ }^{* 1}$, Zhiqiang Zhang ${ }^{2}$ and Lixin Liao ${ }^{1}$ \\ ${ }^{1}$ Northeast Agricultural University, Harbin 150030, Heilongjiang, China \\ ${ }^{2}$ Anhui Jianzhu University, Hefei 230601, Anhui, China \\ Corresponding author: Chuanming Yang, yangchuanming1980@163.com
}

\begin{abstract}
This paper makes a detailed information visualization analysis of the intercultural communication research papers downloaded from 2006 to 2015 in the CSSCI (Chinese Social Sciences Citation Index) by using the most famous information visualization analysis software CiteSpace $V$, which aims to clarify the evolutionary trajectory of the domestic intercultural communication research, to describe the research trends, characteristics, hot spots, the total cited literature and so on, and to reveal the dynamic development of intercultural communication academic research.
\end{abstract}

Keywords: Information visualization, Citespace, Intercultural communication, Dynamic development

\section{Introduction}

Information visualization has been developing at great speed with its advantage of transforming data information into visual form by visual observation and cognition. With the development of information visualization, the researches make applications of its method technology are becoming more and more popular. At the same period, the research on intercultural communication in China has been developing continuously in recent years, but all the studied of intercultural communication in China still takes little care about the dynamics of international academic circles, which causes less study results on intercultural communication in China. This paper uses the visualization technology of metrology to examine the international cultural communication papers published by CSSCI periodicals from 2006 to 2015. It tries to clearly show the present situation, hotspots and development trends of intercultural cultural communication research in China, which is of great significance and inspiration for guiding intercultural cultural communication research in the country. 


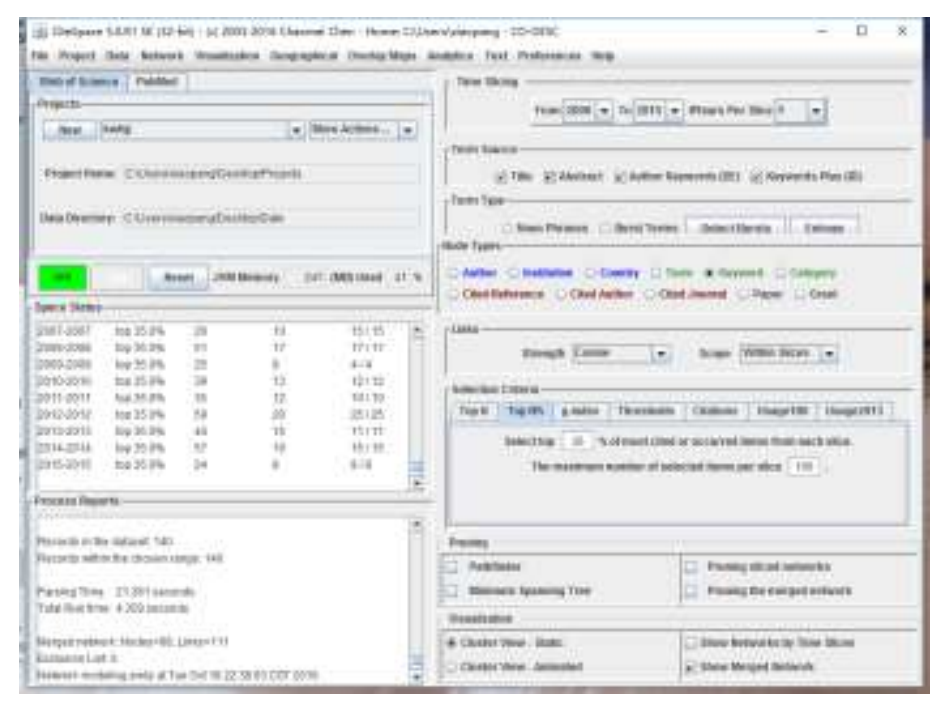

Figure 1. Citespace

\section{Literature Review}

\subsection{Information Visualization}

The term "information visualization" first appeared in Cognitive Coprocessor for Interactive User Interfaces published in 1989 by Robertson etc. The so-called information visualization refers to enhance people's awareness of abstract information by the use of computers to achieve the interactive visual representation on abstract data. Information visualization is the application of visualization technology in the field of non-spatial data. It is a process of transforming data information into visual form by visual observation, cognition and processing. It can enhance the effect of data presentation and make users interact with each other intuitively when observing and browsing the data, which could find hidden features in the data, relationships and patterns and finally analyze data, find rules and make decisions.

In the 20th century, the progress of computer technology has expanded the ability of data processing which could provide a variety of interactive way to help users more easily observe their own interest data. Meanwhile the applications of visualization is more extensive, including data mining visualization, data visualization, social visualization, traffic visualization, text visualization, biomedical visualization and so on. At present, although the visualization of information is still in the development period, the research and applications of its method technology are becoming more and more mature, which brings fundamental change to the information resource management science. 


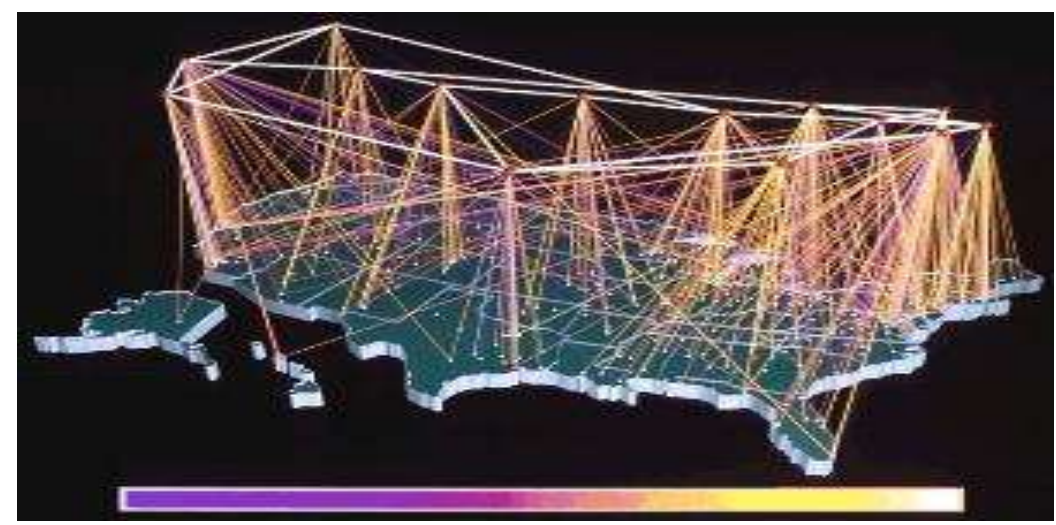

Figure 2. Information Visualization

\subsection{CiteSpace}

The CiteSpace software system is an information visualization software developed by Dr. Chaomei Chen, a Chinese scholar of the Institute of Information Science and Technology at the University of Dresden. The CiteSpace software system can be used to measure and analyze data, to draw the knowledge map on the development of the science and technology and to show intuitively the scientific knowledge of the field of information panorama. And it also can identify the key documents, hot research and cutting-edge direction in one of the scientific fields. It uses the time-sharing dynamic visual map to show the macroscopic structure of scientific knowledge and the way of its development, which is the perfect combination of science and art. The CiteSpace software system was first developed in 2004. It could be scientific and effective and also easy to use in the practical application. Because of rich and beautiful visual effects, it has been widely used in the field of information science at home and abroad. The first article introduced the CiteSpace software by Dr. Chen Chaomei was published in the Proceedings of the National Academy of Sciences (PNAS) in 2004. In 2006, CiteSpace II was published and the article on CiteSpace II was published in the Journal of the American Institute of Information Science and Technology (JASIST). At home, the published articles on the application of CiteSpace software were mainly in the library and information science, science and technology management, computer software, enterprise economics and other disciplines in nearly 100 kinds of journ als. At the same time, CiteSpace as an important document retrieval and analysis tool in the field of science and technology has been widely introduced and promoted. And it was Dr. Chen Chaomei who published the most papers on using CiteSpace software abroad. In addition to the above-mentioned two papers, Dr. Chen Chaomei used CiteSpace software many times in his academic papers and manuscript writing to show the knowledge basis or research front of specific subject areas and to dig out the important documents and its academic influence. For example, Dr. Chen Chaomei and others used CiteSpace with the combination of text analysis to visualize the research trends in the emerging field of regenerative medicine in the latest paper. Among them, it even predicted out the 2012 Nobel Prize in Physiology or Medicine Award winner Yamanaka's important academic position, because his paper that helped him win the prize possessed the incomparable outstanding performance while compared with other papers. This empirical study showed that CiteSpace software played an important role in document mining. At the beginning of 2007, CiteSpace information visualization software was introduced into China. 
Since 2008, CiteSpace's information visualization software has been widely used in China, and the output literature of applied research has grown rapidly.

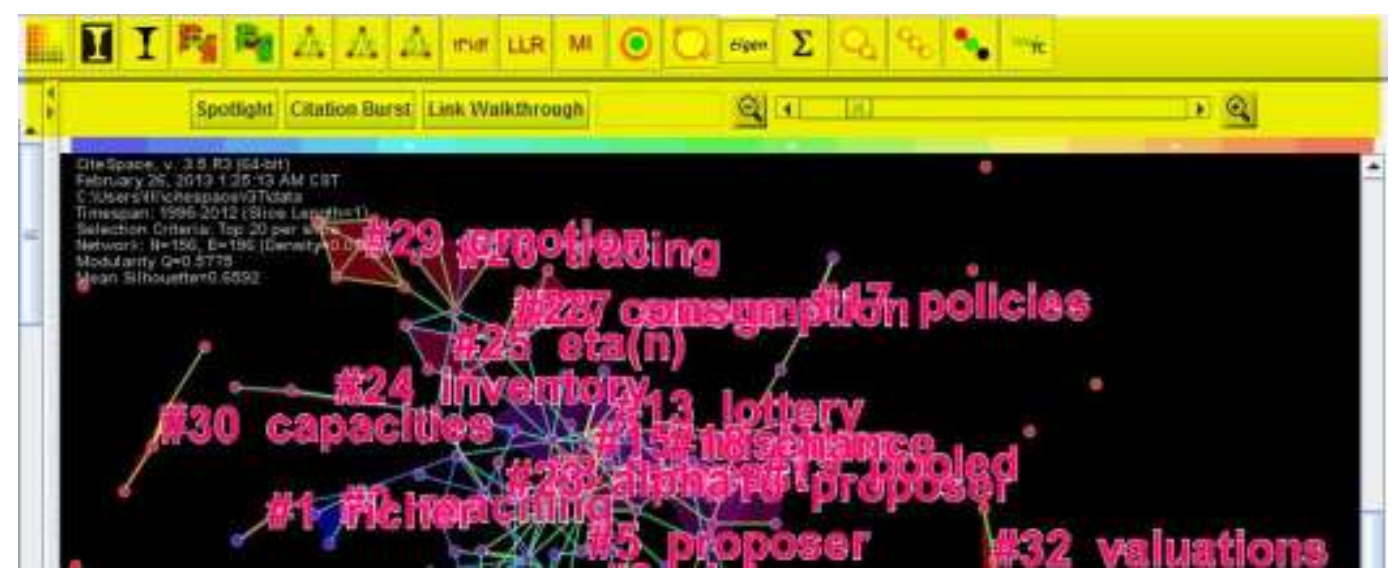

Figure 3. Results of Ctiespace

\section{Intercultural Communication Theory}

Communication refers to the process of exchanging information, influencing each other and constructing the meaning and identity together among people. And intercultural communication that is based on communication emphasizes on communicating among different cultural groups and different cultural members. Moreover, the identity among communicators is the main indicator of intercultural communication. If communicators who agree with their cultures communicate with each other as their cultural spokespersons, the communication among them is intercultural communication.

Anthropologist Robert F Murphy pointed out that a culture often contained a variety of different or even conflicting behavior or values, but it always had its inherent consistency. Ruth Benedict, an anthropologist, in his influential masterpiece cultural model analyzed the diversity of human behavior and the infinity of the diversity. But a tribe and a culture in the infinite possibilities could only choose some of them, and this choice had its own value orientation.

For more than half a century, scholarly enthusiasm for intercultural communication research has spread from the United States to Europe and Asia, soon after throughout the world. Scholars in various countries have made great achievements in cross-cultural communication research.

\subsection{Intercultural Communication Studies in the United States and Europe}

The origin of intercultural communication studies could be traced back to the United States in the 1950s. The objective reason why its birthplace was the United States was to solve the problems that Americans faced in intercultural communication. Many scholars called Edward Hall, the American anthropologist, the father of intercultural communication and regarded his book The Silent Language (1959) as the foundational work on the study of intercultural communication. Edward Hall did much research on the relationship between culture and communication. In the book, Hall not only clarified the relationship between culture and communication, but also proposed a more systematic and scientific cultural research ideas and methods. Soon Hall wrote a series of books on 
intercultural communication, such as Beyond Culture (1967) etc, which made outstanding contributions to cross-cultural communication.

In the 1970s, intercultural communication had completely established its important position in the academic field and become an independent discipline. From the 1970s to the 1980 s, there was a great number of works on intercultural communication written by American scholars published. Among them, the most representative works included An Introduction to Intercultural Communication by J. Condon and F. Yousef in 1975 and Intercultural Communication: A Reader by Samovar and R. Porter in 1982.

In the 1980s, cross-cultural communication in the United States had developed into a system of disciplines. Intercultural Communication Theory: Current Perspectives by Gudy kunst published in 1983, was regarded as a sign of intercultural communication as an independent, mature discipline. The research of this period was mainly focused on two aspects: one was to verify the existing communication theory; the other was to explore the cultural connotation and construct a new theory of intercultural communication.

Communication and Cross-cultural Adaptation: an Integrative Theory by Kim published in 1988 represented the mainstream of cross-cultural studies in his times. He constructed the cross-cultural theory rather than described specific cultural phenomena. His research has contributed greatly to the formation of the theoretical framework of intercultural communication. In the 1990s, Hall proposed the "Emic and Culture-specific Research Method", which was called the micro-cultural research method. This research method focused on analyzing and describing specific cultural phenomena and collecting data, which provided the basis for the construction and practice of intercultural communication theory, thereby ensuring the scientificity and practicability of intercultural communication.

Although the same as English-speaking countries, universities in the UK that open the intercultural communication courses are less when compared with American universities; however it does not mean that English scholars pay no attention to the intercultural communication problems. On the contrary, there are many works on the cultural problems from different perspectives in Britain, including The English Theory of Culture by Malinowski, Key Words: A Vocabulary of the Society and Culture by R. Williams, as well as many other works, which is of great significance for us to understand intercultural communication.

\subsection{Intercultural Communication Studies in China}

Generally from the beginning of the eighties of the twentieth century, China began to study Intercultural communication and only had a short history. It was Professor Guozhang $\mathrm{Xu}$ who made the early introduction of intercultural communication studies to China. His paper entitled Culturally-loaded Words and English Language Teaching published in the journal Modern Foreign Languages in 1982 could be regarded as the earliest discussion of language and culture in China. Since then, cross-cultural communication research in China quietly rose and more and more intercultural communication articles gradually appeared on academic journals. However, it was Professor Wenzhong $\mathrm{Hu}$ at Beijing Foreign Studies University and Professor Shijie Guan at Peking University firstly and systematically introduced the cross-cultural communication as a new discipline to China's foreign language teaching field and linguistics field. In later studies, Professor Yuxin Jia at Harbin Institute of Technology and Professor Zhenya Wang at Beijing Language and Culture University also had a great impact on it. Through these scholars in the domestic system, most of scholars of our country have gained a basic understanding of intercultural communication theory, and they began to do the relevant researches gradually. 


\section{Application of CiteSpace $V$ in the study of Intercultural Communication Theory}

\subsection{Material and Data}

In this study, the visualization analysis software CiteSpace V is used as the main means to study the latest dynamics from the trends, characteristics, the hot key words, the key-node references, the co-citation literature and so on. And the specific methods used in the study include drawing knowledge map, extracting documents with key nodes, and using key-word clustering. The data of the papers are from the CSSCI (Chinese Social Sciences Citation Index) periodicals, and the retrieval period of the keywords is from 2006 to 2015 for total 10 years. After the data cleaning processing, there are a total of 172 papers on intercultural communication. The data contain information about authors, titles, source publication, abstracts, references and so on.

\subsection{Results and Discussion}

(1)Overall trends and characteristics: Statistics show that over the past 10 years, the total number of 172 papers published in CSSCI journals has been increasing year by year, with cyclical ups and downs, especially in 2008, 2009, 2014 and 2015 (see figure 1). Among them, the amount of intercultural communication papers published in the domestic reached the maximum in 2008 and 2014, while dropped significantly in 2009 and 2015.

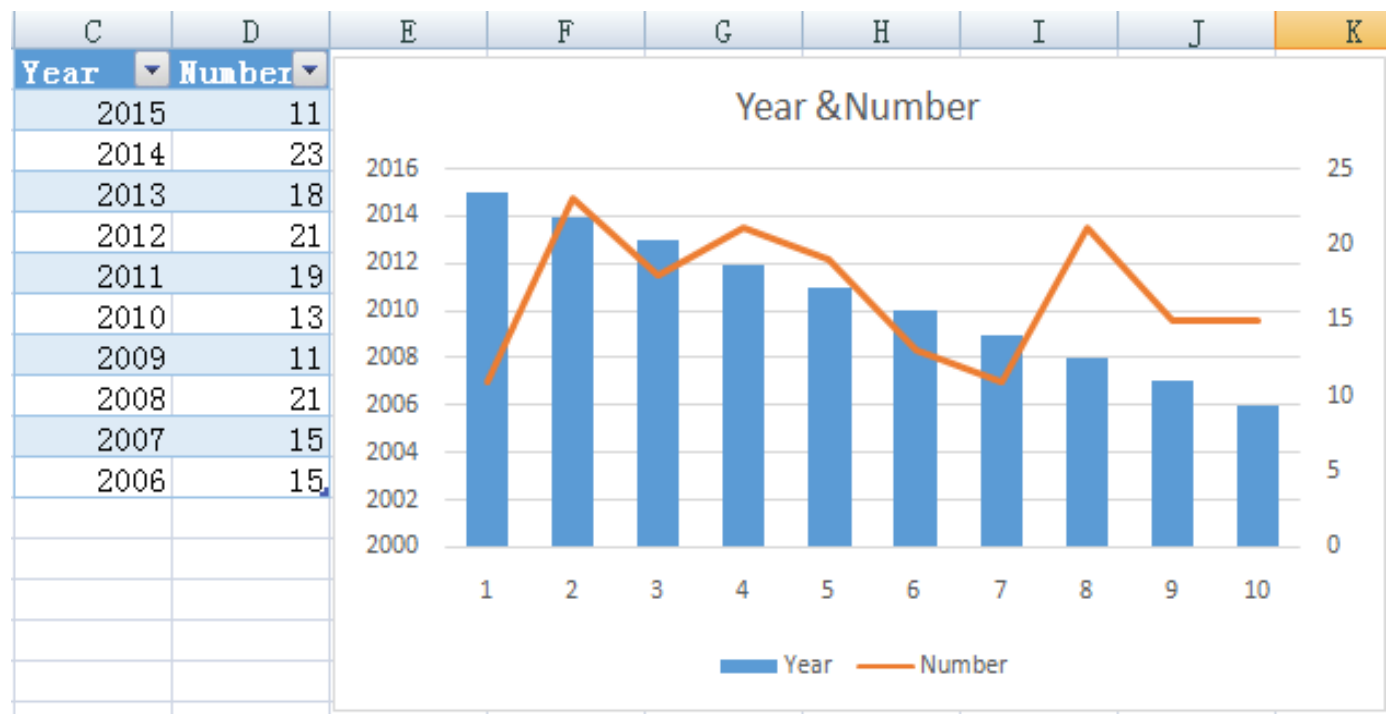

\section{Figure 4. Trends in the Intercultural Communication Research of CSSCI (2006-2015)}

The classification of journals statistics shows (see Figure 2)that the top 10 areas of the published intercultural communication papers of CSSCI periodicals are: (1) Linguistics; (2) Foreign literature; (3) Chinese literature; (4) Religious science; (5) Arts; (6) Ethnology; (7) Economics; (8) Politics; (9) History;(10) Philosophy. As the graph indicates, the distribution of disciplines is heavily uneven: 89 of 172 papers published are related to linguistics, which accounts for $51.7 \%$ of the total published papers; while only 1 to 3 papers involving the rest of areas. 


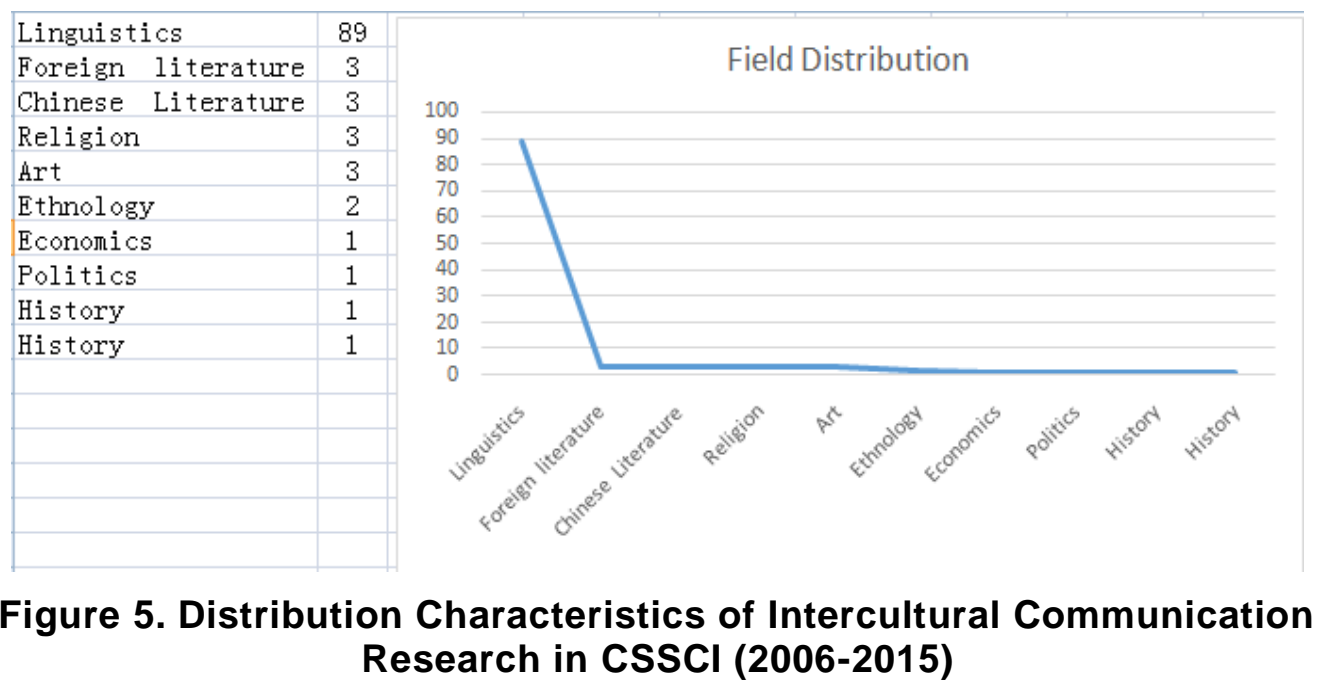

(2) Map analysis of visual knowledge domains on the research hotspots: Figure 3 shows that over the past 10 years, the intercultural communication researches in CSSCI have focused on 20 key words, and according to the order from high to low include: ability of intercultural communication, cultural awareness, intercultural communication, intercultural communication intention / relevanceadaptation, foreign readers, one-to-one digital learning, characteristics of a second language, cultural confidence / Chinese Muslims, intercultural communication theory, pragmatic failure, foreign language teaching, ethnic minority areas, Chinese classic books, study on intercultural communication, university students' ability of intercultural communication, constructivism, theory of intercultural communication, evaluation /intercultural communication courses, word relevancy, and Chinese and Western cultures.

For the analysis of hot spots in the research, we need to set time slicing to 20062015 and years per slice to 1 , so we get 10 time periods.

Firstly, checking the title, abstract, authour keywords (DE), keywords plus (ID) in the term source, and then the term and keyword in the node types. Secondly, selecting top N\% mode in the selection criteria and the parameter is set to select top $25 \%$ most cited items from each slice and the maximum number of selected items per slice 100. Finally, the output of the network is covered by the nodes (nodes = 68 ) and the connection line (links $=69$ ).

After clustering with Citespace, the study uses cluster label to get the result - the value of modularity is 0.6885 and mean silhouette is 0.4238 . When $q$ (the short name of modularity) is greater than 0.3 , it is considered that the community structure is obvious; the average contour value is usually above 0.5 , which is perceived to be reasonable, but it will be slightly reduced when the data sample is small. 


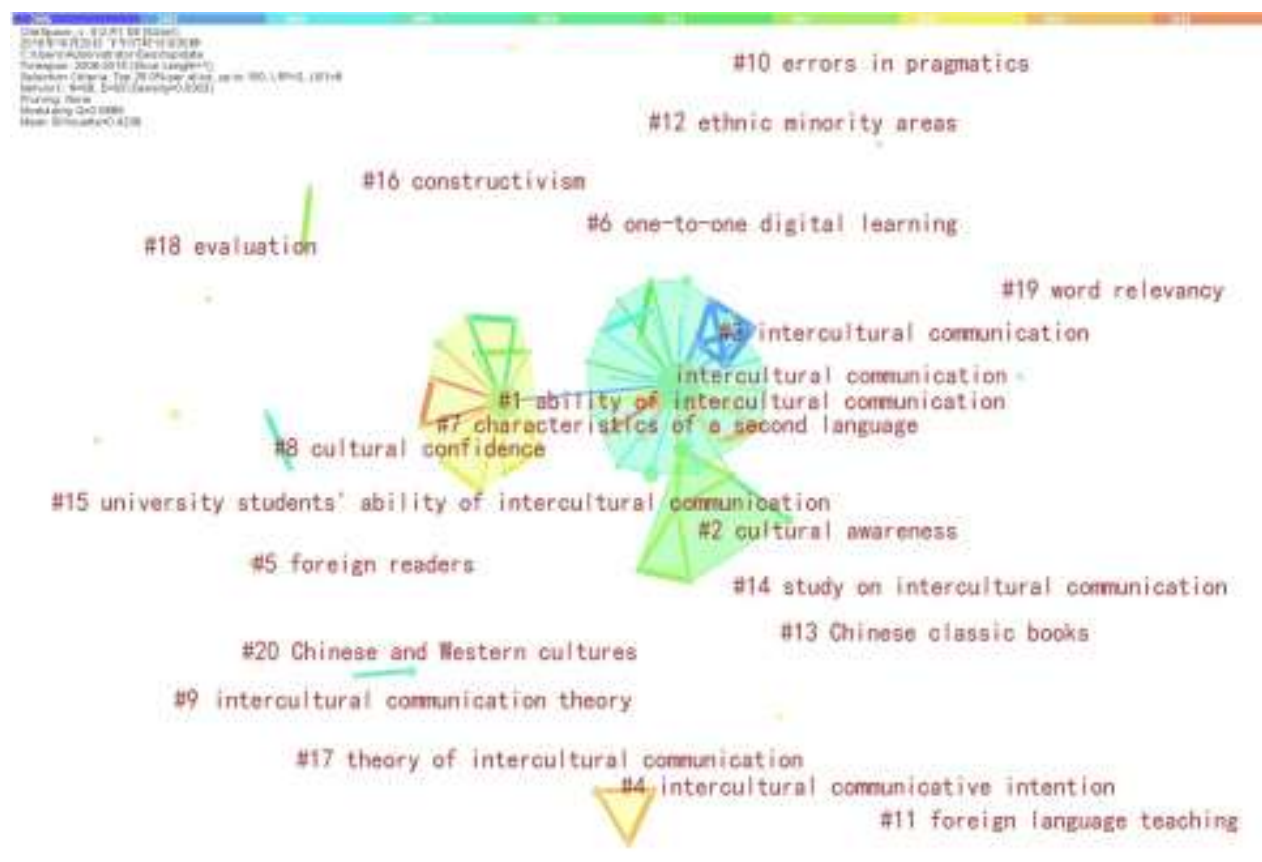

Figure 6. Visualization Co-occurrence Knowledge Map of the Intercultural Communication Research Hotspots in CSSCI (2006-2015)

We find that the key words of intercultural communication papers in CSSCI mainly focus on intercultural communication, ability of intercultural communicative, foreign language teaching, differences of cultures, communication strategies, English teaching, globalization, errors of intercultural communication, courses of intercultural communication, cross cultures, intercultural communication intention, and Chinese university students. In particular, the vast majority concentrate in intercultural communication and ability of intercultural communicative. (See Table 1)

\section{Table 1. Word Frequency of the Intercultural Communication Hotspot Keywords in CSSCI (2006-2015)}

\begin{tabular}{|c|c|c|c|}
\hline Freq & Centrality & Year & Cited References \\
\hline 72 & 0.76 & 2007 & intercultural communication \\
\hline 28 & 0.40 & 2007 & ability of intercultural communication \\
\hline 4 & 0.00 & 2008 & foreign language teaching \\
\hline 4 & 0.00 & 2012 & differences of cultures \\
\hline 3 & 0.08 & 2011 & communication strategy \\
\hline 2 & 0.00 & 2008 & English teaching \\
\hline 2 & 0.04 & 2010 & globalization \\
\hline 2 & 0.00 & 2010 & errors of intercultural communication \\
\hline 2 & 0.00 & 2013 & courses of intercultural communication \\
\hline 2 & 0.00 & 2009 & cross cultures \\
\hline 2 & 0.00 & 2014 & interoultural comunicative intention \\
\hline 2 & 0.00 & 2014 & Chinese university students \\
\hline
\end{tabular}

(3) Network map analysis of the key nodes references: If the more papers cite one reference, this reference will have the higher center degree and the greater influence when the citation frequency is the same. From the perspective of knowledge theory, the key-node references are the literatures that present significant theories or innovative concepts in a certain field, and are also the key literatures 
which are most likely to cause new research hotspots. By analyzing the key-node references in intercultural communication, we find out the most cited papers or authors. And they have the greatest impact on intercultural communication research.

As shown in Figure 4, Intercultural Communication by Professor Yuxin Jia in Harbin Institute of Technology in 2006 was the most cited reference by other papers on intercultural communication and had the most influence in the past 10 years.

\section{Figure 7. Co-citation Network Map of the Intercultural Communication Key-node References in CSSCI (2006-2015)}

As shown in Table 2, the top five cited intercultural communication papers published in CSSCI journals from 2006 to 2015 included: Intercultural Communication by Jia Yuxin, Intercultural Communication Series by Wenzhong $\mathrm{Hu}$, Intercultural Approach to Foreign Language Teaching by Hongling Zhang, Communication Between Cultures by Samoverlar. La and Teaching and Assessing Intercultural Communicative Competence by Byram M. Among the five references, Yuxin Jia's and Wenzhong Hu's books were the most highly cited. These two books were respectively cited 28 times and 21 times in 2006.

\section{Table 2. The List of the Top 5 Cited Intercultural Communication Key-node References in CSSCI (2006-2015)}

\begin{tabular}{|c|c|c|c|}
\hline Freq & Centrality & Year & \\
\hline$\sqrt{28}$ & 0.16 & 2006 & YCTIN JIA, 2006, INIERCLLTRALCOWTIICATION \\
\hline$\sqrt{2} 21$ & 0.05 & 2006 & 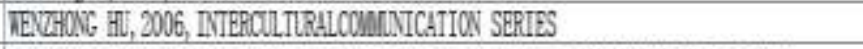 \\
\hline$\sqrt{9} 9$ & 0.12 & 2006 & 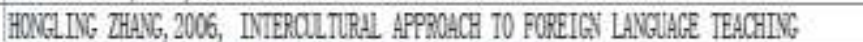 \\
\hline$v^{7}$ & 0.13 & 2006 & 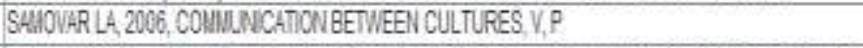 \\
\hline$\sqrt{\nabla} 6$ & 0.10 & 2006 & 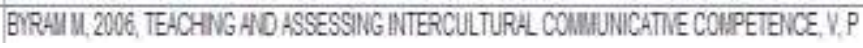 \\
\hline
\end{tabular}

We further analyze the historical evolution of key-node references (see Figure 5 and Figure 6).It focuses on the specific cases in which the cited books written by Yuxin Jia and Wenzhong Hu to find the involved authors and linguistic theories, and deduce whichever has made the greatest contribution to intercultural communication research.

Figure 5 and Figure 6 show that domestic scholars such as Hongling Zhang, Guoming Chen, Lisheng $\mathrm{Xu}$, Ying Yang and foreign scholars such as Samovar Larry 
A, Byram M, Chen (Guo-Ming) and Scollon R, etc, have all made outstanding contributions to intercultural communication research.

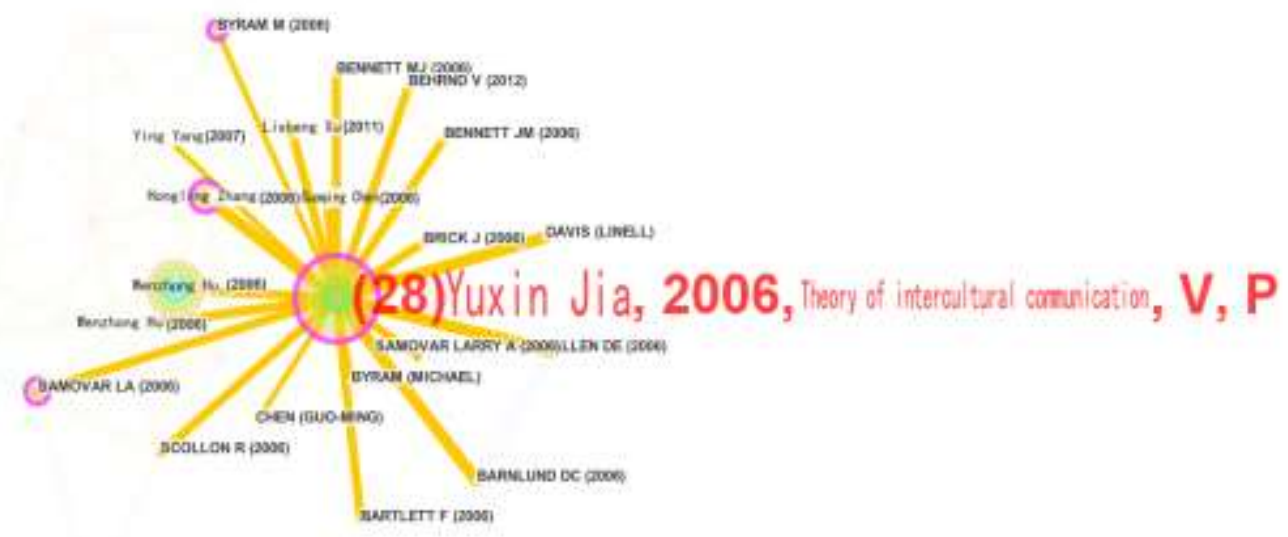

Figure 8. Citation Map of the Intercultural Communication Key-node Reference by Yuxin Jia

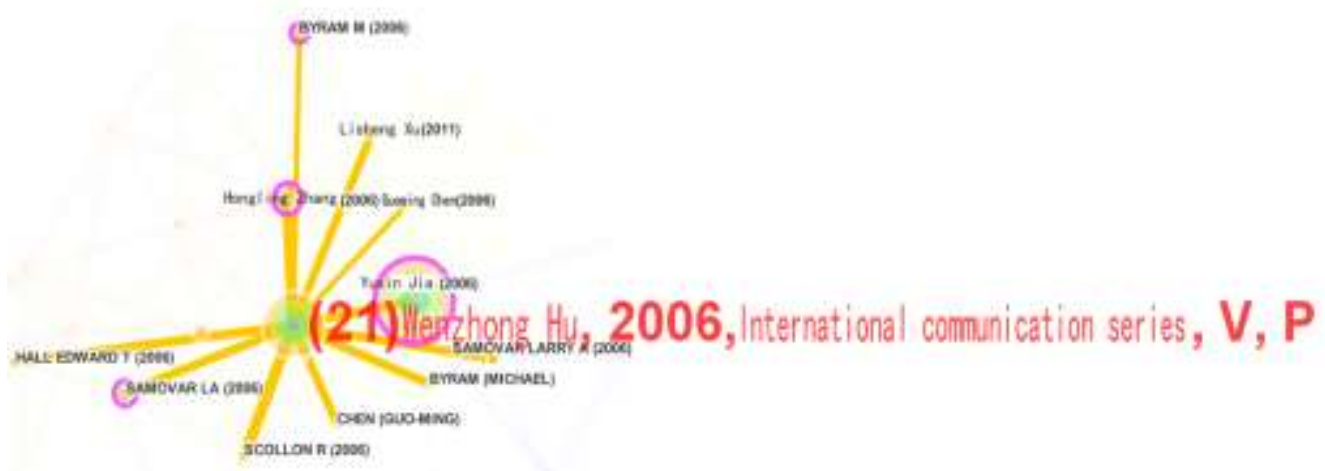

Figure 9. Citation Map of the Intercultural Communication Key-node Reference by Wenzhong Hu

\section{Conclusion}

By investigating and analyzing the hotspots and progress of intercultural communication research of CSSCI periodicals from 2006 to 2015, the results of this study show that: (1) the total number of 172 papers published in CSSCI has been increasing year by year, accompanied by periodic up-and-down waves, especially in 2008, 2009, 2014 and2015; (2) the classification of the journal statistics shows that the top 10 areas of the papers on intercultural communication published in CSSCI are linguistics, foreign literature, Chinese literature, Religious science, Arts, Ethnology, Economics, Politics, History and philosophy; (3) The frequency search of key word indicates that the intercultural communication hotspot keywords of CSSCI periodicals are mainly concentrated in: ability of intercultural communication, cultural awareness, intercultural communication, intercultural 
communication intention / relevance-adaptation, foreign readers, one-to-one digital learning, characteristics of a second language, cultural confidence / Chinese Muslims, intercultural communication theory, pragmatic failure, foreign language teaching, ethnic minority areas, Chinese classic books, study on intercultural communication, university students' ability of intercultural communication, constructivism, theory of intercultural communication, evaluation /intercultural communication courses, word relevancy, and Chinese and Western cultures; (4) the top 5 cited cross-cultural communication papers published in CSSCI journals are: Intercultural Communication by Jia Yuxin, Intercultural Communication Series by Wenzhong $\mathrm{Hu}$, Intercultural Approach to Foreign Language Teaching by Hongling Zhang, Communication Between Cultures by Samoverlar. La and Teaching and Assessing Intercultural Communicative Competence by Byram M. This research excavates the dynamic development of the intercultural communication academic research of CSSCI periodicals, and has certain reference and enlightenment to clear the hotspots and directions of domestic intercultural communication research.

\section{Acknowledgments}

This study was financially supported by 2015 Research Projects on Philosophy and Social Sciences of Heilongjiang Province, Multiple Needs Analysis of General Education in College English (15YYB07); 2016 Research Projects on Educational Reform of the Academic Degree and Postgraduate Education of Heilongjiang Province, the Development of Postgraduates' English Education from the Perspective of Supply-side Reform(JGXM_HLJ_2016074).

\section{References}

[1] B. Bederson and B. Shneiderman, "The craft of information visualization: readings and reflections", San Francisco: Morgan Kaufmann Publishers, (2003), pp.66-68

[2] G. G. Roberson, S. K. Card and J. D. Mackinlay, "The cognitive co -processor for interactive user interfaces”, In Proceedings of UIS'89, ACM Symposiom on use interface and software and technology, New York, USA: ACM Press, (1989), pp.81-89

[3] C. Chen, "Searching for intellectual turning points: Progressive knowledge domain visualization", Journal of PNAS, vol.101, no. 1, (2004), pp.5303 -5310.

[4] C .Chen, "CiteSpace II: Detecting and visualizing emerging trends and transient patterns in scientific literature", Journal of the American Society for Information Science and Technology, vol.57, no, 3, (2006), pp.359-377.

[5] C. Chen, Z. Hu, S. Liu and H. Tseng, "Emerging trends in regenerative medicine: a scientometric analysis in CiteSpace", Journal of Expert Opinion on Biological Therapy, vol.12, no.5, (2012), pp.593 608.

[6] E.T. Hall, "Beyond Culture. New York: Doubleday”, (1976), pp.38-56.

[7] E.T. Hall, "Silent Language. New York: Doubleday", (1995), pp-55-68.

[8] J.C. Condon and F. S. Yousef, "An Introduction to Communication (3rd ed.)", Indianapolis: BobbsMerrill Company, (1975), pp.56-69.

[9] L.A. Samovar and R.E. Porter, "Intercultural Communication: A Reader", Belmont, Calif: Wadsworth, (1982).pp.36-39.

[10] Gudykunst, W.B., "Intercultural Cmmunication Theory: Current Perspectives", Beverly Hills, CA: Sage, (1983), pp.68-89.

[11] Y.Y. Kim, "Communication and Cross-cultural Adaptation: an Integrative Theory", England: Multilingual Matters, (1988), pp.55-65.

[12] B. Malinowski, "A Scientific Theory of Culture and Others Essays", Chapel Hill, N. Carolina: The University of North Carolina Press, (1944), pp.111-116.

[13] R. Williams, "Keywords: A Vocabulary of Culture and Society", London: Fontana/Croom Helm, (1976), pp.81-89. 


\section{Authors}

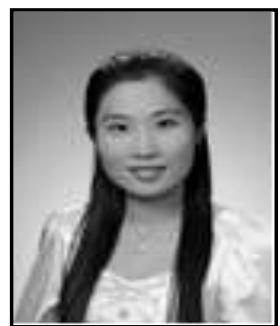

Yang Chuanming, (1980.01), she was born Harbin, Heilongjiang, China, her ccurrent position is an associate professor of College Humanities and Law, Northeast Agricultural University, Heilongjiang, China, Her research interest fields include linguistics, intercultural communication and English education. She has more than more than 10 papers published. She has teaching experience of 14 years, has completed 6 secientific research projects. 